\title{
Extending the concept of the morphological frame: A case study of Tangshan old military airport
}

\author{
Rongxi Peng, Zijiao Zhang, Yixi Li, Feng Song* \\ College of Urban and Environmental Sciences, Peking University. Beijing, China \\ *(corresponding author) \\ E-mail: pengrongxi@pku.edu.cn,1300013269@pku.edu.cn, elaine9565@yeah.net, \\ songfeng@urban.pku.edu.cn
}

\begin{abstract}
The concept of morphological frame is important in urban morphology, but it has been discussed much less than other critical concepts, such as the fringe belt and the fixation line. Passing its features on as inherited outlines, the morphological frame contains not only the linear fixation line, but also ground plan and three-dimensional aspects. In this research, the linear, ground plan, and three-dimensional morphological frame of Tangshan old military airport during the expansion of the city after the removal of the airport is identified. The former boundary roads of the airport exert obvious influences on the division of plots. The former arterial roads also function as a linear morphological frame. In relation to the ground plan, property rights and plots containing important buildings have an impact on the consequent town plan. The distinct feature of the morphological frame of the airport is its three-dimensional constraint, i.e. the vertical clearance requirement, which restricted the height of surrounding buildings. The impact of this institutional limit can last a very long time owing to the high cost of demolishing the old surrounding buildings or adding extra storeys even if the limit ceased to exist with the removal of the airport. Based on this case study, this paper refines and extends the connotation of the concept of the morphological frame and further discusses the relationship between three kinds of it.
\end{abstract}

Keywords: China, morphological frame, three-dimensional view, airport

\section{Introduction}

Morphological frame is an important concept in urban morphology field. Although there are more discussions on fixation line, the definition and connotation of morphological frame may be much more general. The concept of morphological frame contributes a lot to the analysis and explanation of the connection between former existence and later development pattern in townscape. Even though there are some extension and deeper research on morphological frame after Conzen's definition, due to the limitation by the time and region background-a small service center in Europe of 1960s - and the particular attention to ground plan of Conzenian school, some important aspects of morphological frame are still not elaborated yet such as its tridimensional features. In this article, the concept morphological frame will be refined based on the research of Tangshan old military airport of China.

\section{Concepts and definitions}

Morphological frame was put forward by M.R.G. Conzen in 1960 in his works Alnwick, Northumberland: A study in town-plan analysis. The initial definition of morphological frame is "an antecedent 
plan feature, topographical outline, or set of outlines exerting a morphological influence on subsequent more or less conformable plan development, and often passing its features on as inherited outlines" (Conzen, 1969).

In the research of Alnwick, Conzen referred to morphological frame in several places. In the part of borough extension, Conzen mentioned that the Bow Burn acted as a morphological frame which introduced an only informal element into the plot pattern of Pottergate area, especially the easternmost burgage laying right alongside the brook. The Bow Burn could be defined as a linear morphological frame, which impacts the morphology of the division of plots.

When analyzing the pattern of fields, a lot of former elements were remained as residues in later plan. In Conzen's words, "at successive stages the field pattern surrounding the Old Town appears as a formative factor in the evolution of the street-plan", "it serves as $\mathrm{s}$ guiding framework for subsequent development, determining the topographical detail of later plan features". Even though the fields were assimilated by the town, due to property rights and economic considerations, the boundaries and field lanes usually served as a limit of later plan-units. This kind of morphological frame is different with the linear one as street, but as a former ground plan restrains the later one. So, it could be defined as planar morphological frame.

Generally, these two kinds of morphological frames affect later town plan simultaneously.
For example, in the case of Alnwick, the road and the Easter Piece field act as morphological frame together to the single-sided ribbon on the east side of the ancient field-lane leading southward from Green Batt. The real boundaries like roads and rivers and more intangible limits such as property rights both restrain the ribbon development in this case.

Besides these artificial frames, rapid gradient changes or rivers could also exert influences on later town plan, which are called "topographical outlines" by Peter Larkham and Andrew Jones. For instance, in the case of an Italian city Como, the location and morphology of frame is restricted a lot by the adjacent hills and lake (Whitehand et al., 2016), i.e. the Alpine mountains and Lake Como both act as topographically morphological frame to the city Como.

Whether Conzen or later researchers all focus on the planar properties and impacts of morphological frames, without little attention to tridimensional ones. What's more, because of a more rapid urbanization and a much stronger government than western countries, it is necessary for Chinese cities to investigate the morphology changes after the removal of morphological frames.

\section{Tangshan old military airport}

Tangshan, located in northeastern Hebei Province, is one of the center cities in BeijingTianjin-Hebei metropolitan region. Although

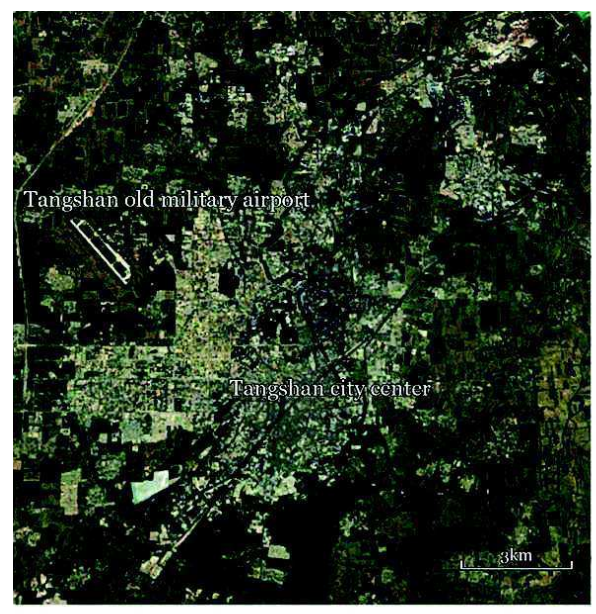

$1-a$
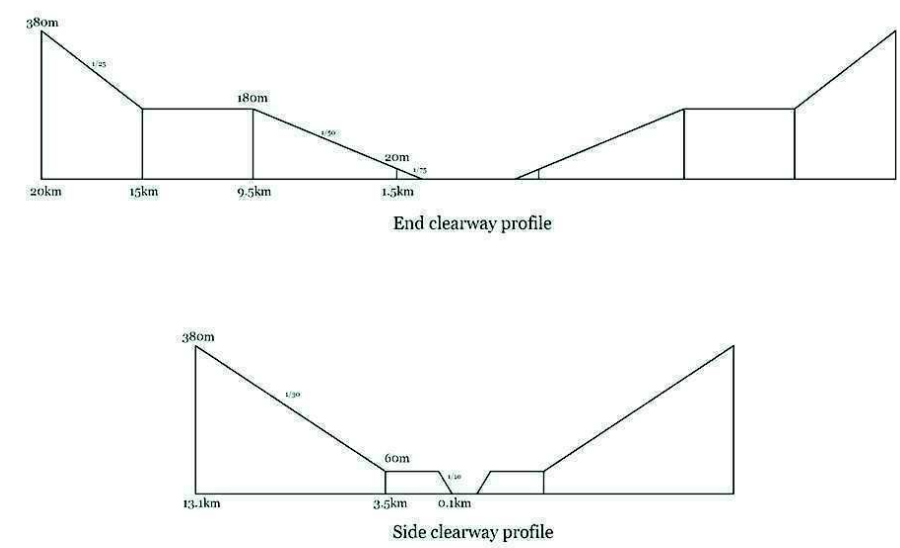

$1-\mathrm{b}$

Figure 1.

The location and airport protection overlay of Tangshan old military airport. 
Tangshan old military airport was built before the foundation of People's Republic of China (1949), it was repaired and enlarged in 1950 to protect Beijing and support North Korea during the Korean War. In 1976, one of the most tragic earthquakes in the history of China hit Tangshan, which killed nearly 250 thousand people. The military airport wasn't severely damaged so that it played important role to contact with outside world including transporting the injured and supplies.

After Chinese economic reform, most Chinese cities including Tangshan developed fast and expanded a lot. As a result, the distance between Tangshan city center and the military airport is so close that the airport restricted the construction of the city especially the northwestern direction because of its requirements about clearance condition
(Figure 1-a). To solve this problem, the Tangshan government and Beijing air force came an agreement about the relocation of military airport in November 1995. According the agreement, the new military airport would be located in a rural county of Tangshan. In 2004, the new military airport started using and the old one was handed over to the government and transferred from military use to urban construction land.

As to the limit of the airport to the city, the Tangshan old military airport was a military class two airport in China, and according to Chinese Military Airports Clearance Regulations, its clearance area should begin from the both edges of taking off and landing strip, and extend 1500 meters as a $15 \%$ gradient (Figure 1-b). Because Tangshan old military airport was northwest southeast direction,
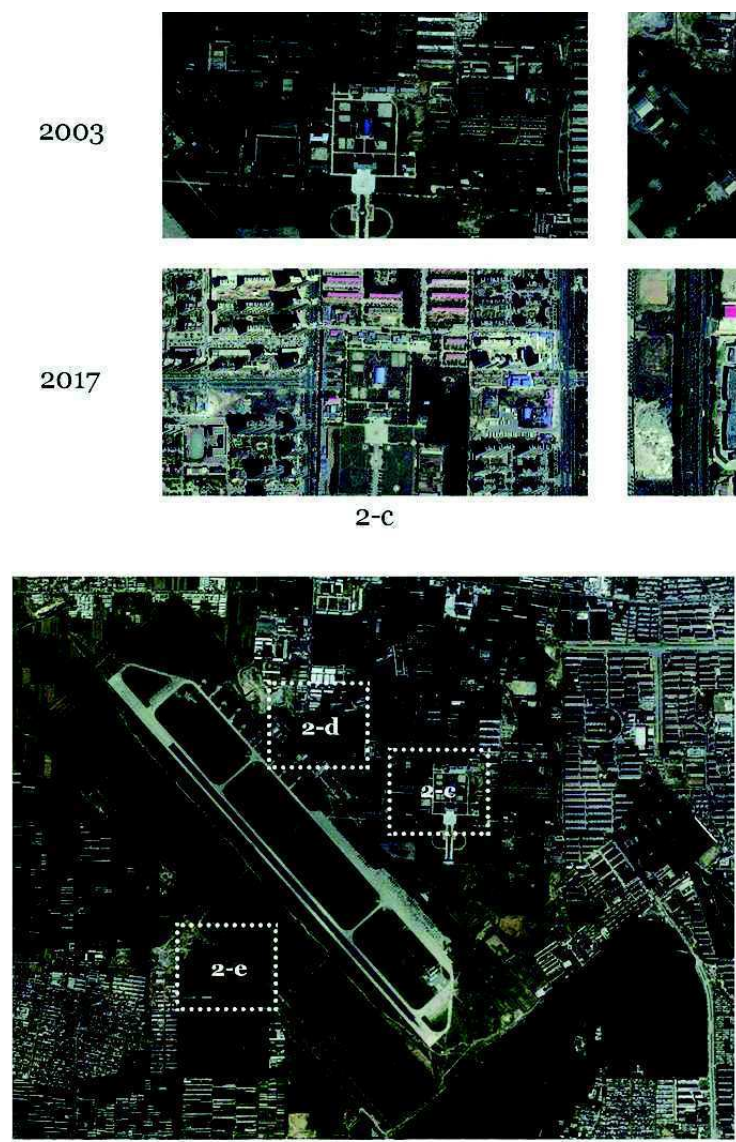

2-a
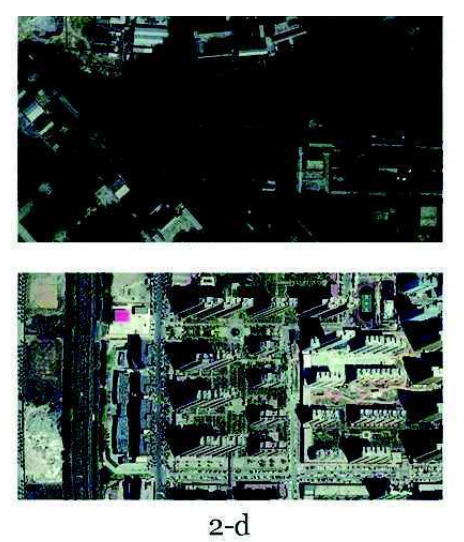
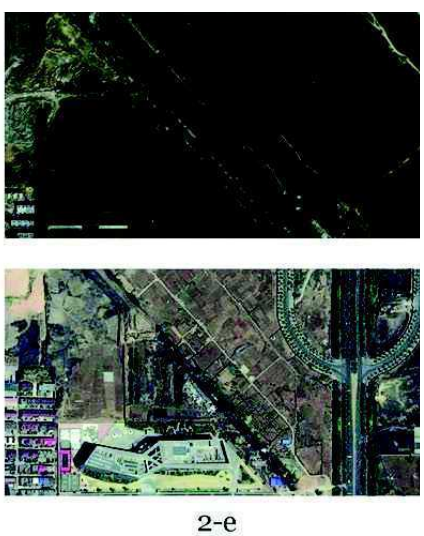

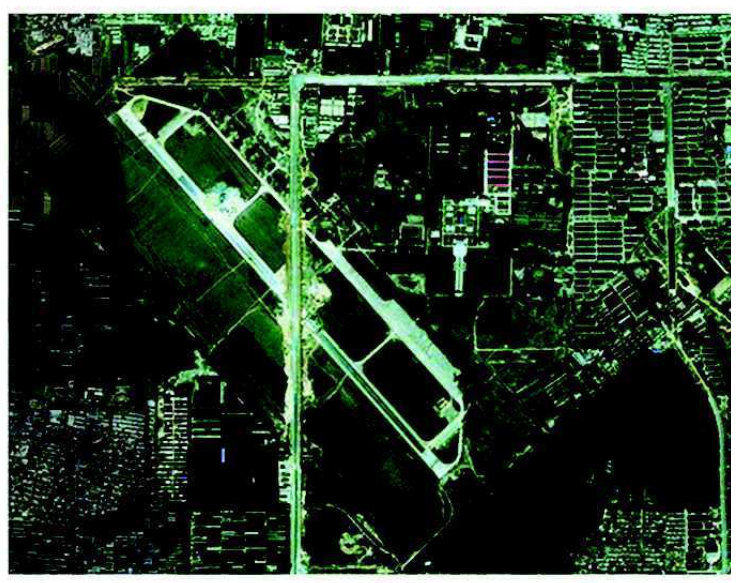

2-b

Figure 2.

Street plan changes

2-a. The old airport in 2003; 2-b. The old airport in 2005; 2-c. Dali North Road; 2-d. Lanes in the North; 2-e. Boundary lanes in the Southwest 
the city construction was constraint in this direction. As a result, before the relocation of the airport, there were almost no tall buildings in clearance area.

Due to the features - the clearance requirement and the process from being used to abandoned - of Tangshan old military airport, it is a good case to study for morphological frame research.

\section{Changes of this area since relocation of the military airport}

To illustrate the changes clearly, we choose three satellite images of 2002, 2009 and 2017 from Google Earth. The satellite images could give us a direct view of the development in a certain area, and further offer us a way to distinguish the plot pattern, fixation line and morphological frame etc. Another advantage of satellite image is that we can estimate the height of buildings from the length of the shadow when there's no available data and the target area is too large to record the height of individual building on the spot.

In the whole developing process, the street plan first changed. With the construction of Youyi North Road and the extension of Changning West Street in 2005, a general street pattern was founded in this area. After the construction of roads, the lands along the road were also developed, with a totally different style and morphology compared to the older buildings. Generally, the southeast and northeast part which is near the built-up area of the city developed earliest, then the lands with low intensity of development in the center of this area were developed, and the southwest part that is near rural area was the last part to change. The change of streets, plots and buildings in the area are tightly connected with each other in the rapid development, which is influenced not only by the former morphological frame but also later capital investment and policy impetus.

\section{Street plan}

Although street plan is thought as the most stable element in urban morphology based on the research of Alnwick, the road network changes more rapidly in the old military airport area after the relocation of military airport in 2004. Due to the particularity of airport, there were few roads inside this plot except those small ones affiliated with buildings or acting as boundaries, which provided the possibility to re-build road system in this area.

In the renewal of street system, the new road especially the arterial roads construction first happened, i.e. the construction of Youyi North Road and Changning West Street (Figure 2-b). Considering the different direction between airport construction and city main roads, respectively northwest-southeast and northsouth, the internal street texture of airport should be changed to adapt the need of city expansion. Although Youyi North Road actually is affected by field pattern outside the airport, i.e. its south part is upgraded from former field lane, it is totally new in the area of airport, regardless whatever existed in its way. What ensured the performance of this drastic change is the strength of government. After meeting the airport relocation agreement, Tangshan government put forward an airport new district plan instantly, including more than 20 square kilometers lands northwest Tangshan containing the airport area, and this new district was later renamed as Phoenix New District. This could explain why the two main roads directly broke former street plan and formed a new frame.

Besides the new roads construction, some planned secondary roads in this area are upgraded from existed lanes, which means that the existed roads are re-built and widened on spot to cater with the plan. For example, Dali North Road was upgraded from an internal small lane in previous airport living quarters due to the same direction with the plan but a not enough width and a bad construction condition (Figure 2-c). This kind of change doesn't influence the existed division of plots, so that it hardly affects surrounding buildings and further cut down on the expenses and improve construction efficiency.

Roads removal is also a major change in this area especially the southeast and north part (Figure 2-d). For instance, in the south part, a new living district thoroughly blots out the 


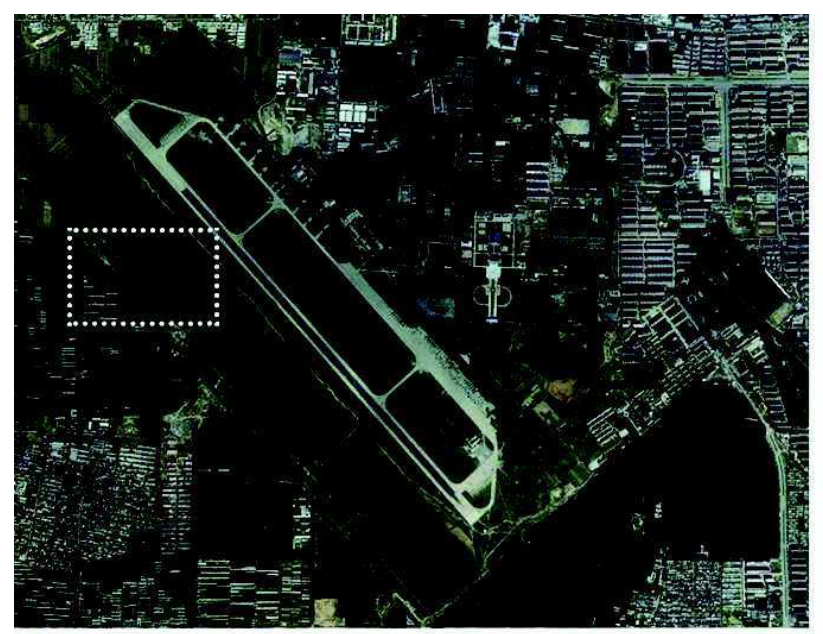

3-a

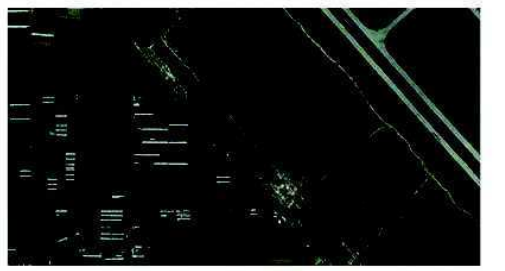

2003

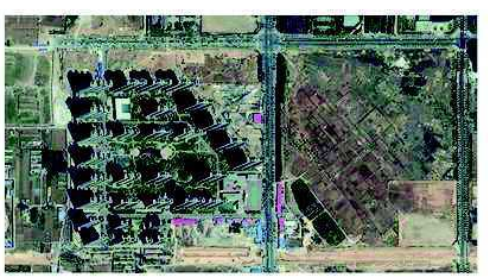

2017

Figure 3.

3-b

Plot pattern changes

3-a. The old airport in 2003; 3-b. Jidong Shiyou Jiayuan

former lanes and rebuilds its own. Those don't accord with the plan and with no buildings beside have a greater possibility to be removed because of a low cost and resistance.

Comparatively, there are also some roads without any change inside the airport. We can distinguish two kinds of these roads. One is those roads acting as temporary boundaries with one or both sides un-renewing such as the southwest boundary of airport (Figure 2-e). They are easy to be removed or changed with the development of this area. The other one is those roads affiliating to certain buildings such as the old auditorium, which are usually very small and only used by the building itself. Maybe these roads could be reconstructed but they are not upgraded and widened.

\section{Plot pattern}

The change of plot division is usually concurrent with that of street plan. If the street is remained or upgraded, the plot division would not change drastically, while when former roads are removed and new roads are created, the plots would be re-divided by the new roads. Overall, the land development sequence was relatively consistent with the road construction, and showed the feature of arterial ribbons in early period.

One particular and interesting case is the plot of Jidong Shiyou Jiayuan (East Hebei Petrol Garden). This plot was divided obviously by the former boundary road and field lanes (Figure 3 ). Due to the lack of related documents, we could not get detailed information about the construction of this residential area, but the building completion sign could inform us that this district was completed in 2008 so that we could deduct that this land might be leased between 2004 to 2006, just after the relocation of old airport. From current satellite image, we can see that although this residential area is located in the cross of two arterial roads, there are still irregular shaped open space between the boundary of it and the roads, which is not common in a city. Considering this plot is not in the old airport but an adjacent village, this phenomenon may be related to the different land sources i.e. the rural collective land expropriation and the land transferred from military use to urban construction using. When the land was leased the two arterial roads hadn't been built, so the plot division could only refer to field lanes, resulting the current irregular plots this area.

\section{Building fabric}

Since the relocation of airport in 2004, a lot of new buildings grew up rapidly due to the removal of clearance requirement and internal street plan in former clearance management area and old airport land, and these new buildings are fairly different from old ones in height, density, volume and direction. 


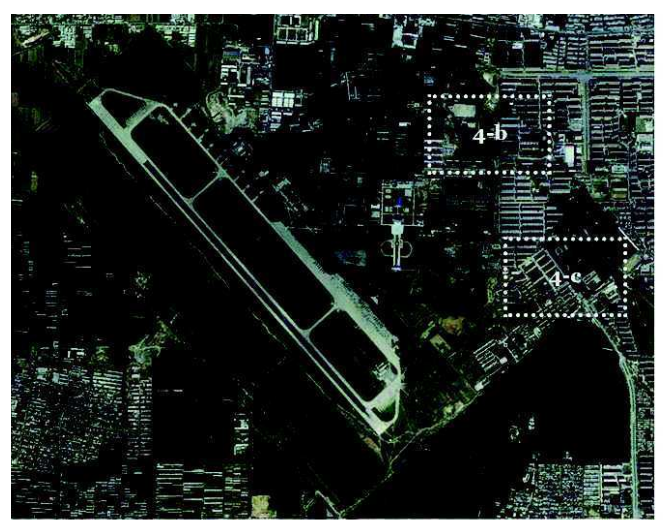

4-a
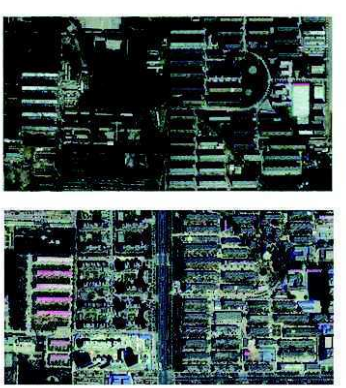

4-b
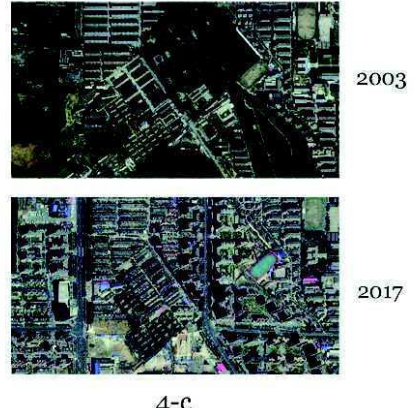

Figure 4.

Building fabrics changes

4-a. The old airport in 2003; 4-b. Xueyuan North Road; 4-c. Airport Road

From the aspect of building height and density, there are some obvious differences among the buildings on the two sides of Xueyuan North Road (Figure 4-b). Xiangrongli Community, already existed before the relocation of airport, is located on the east side with low-rise and high-density features while Yijing Wenyuan which was built after 2009 sits on the west side with relatively higher rise and lower density.

The volume of new buildings tends to be larger than older ones. For example, there were fields and low-rise and volume buildings before in north part of this area but now are bigvolume buildings. These buildings are usually used as government office such as taxation authorities, procuratorate, court and bureau of public security. A big square and open space in front of buildings is also a characteristic of these plots.

One interesting change in this area is the direction of buildings beside Weiguo North Road and the old Airport Road (Figure 4-c). Before the relocation of airport, the Airport Road played an important role in regional transportation so that the Lantian Lou Community is along this northwest-southeast road. After the construction of Weiguo North Road, the current arterial road in this region, the importance of Airport Road declined, resulting the new buildings like Biyu Huafu along Weiguo North Road, although the existence of Airport Road still limits the shape of plots and the arrangement of buildings.

\section{Morphological frame of the airport: linear, planar and tridimensional}

The changes mentioned above are tightly connected with morphological frames. Some morphological frames are the residuals of old airport while there are also some from new built buildings or streets. According to the different features, we could classify the morphological frames into three categories i.e. linear, planar and tridimensional.

Linear morphological frame is the most common one which mainly contains streets and boundaries. The later plot division is not only affected by the residual streets and boundaries but also the new built roads. For example, the plots beside older Airport Road are divided along with this old "irregular" road, which causes the special arrangement of buildings inside plots. The new built roads like Youyi North Road also restricts shape of plots and other features of morphology forcefully. The plot division of Jidong Shiyou Jiayuan mentioned above is a particular case that the former morphological frames i.e. the field lane and airport boundaries exert longterm and strong influence on the later urban plan although this plot division is no longer accordant with the main roads.

Planar morphological frames, or also can be called as ground plan, have strong impacts on the later plan development and construction. We can still put our eyes on the case of Jidong Shiyou Jiayuan here because after the construction of this residential district which 
was influenced by the linear frames, it becomes an existed planar frame that could restrict and affect surrounding construction conditions such as plot division or later ground plan. Both linear and planar morphological frame contributed to the formation of the irregular shaped open space between this residential district and Changning West Street. Due to the different land property of Jidong Shiyou Jiayuan and the open space, this irregular shaped plot division would last for a long time. Another example is the village plot in the cross of Changhong West Street and Guangming North Road. Maybe the villagers didn't meet an agreement with the government on the compensation for demolition, this small village blocks the connection between these two main roads.

In this case, there is also a tridimensional morphological frame of airport i.e. the clearance requirement. The tridimensional frame is not like the visible ones that have direct physical influence on later town plan but an intangible regulation on the construction. For this area, before the relocation of airport, the clearance requirement acted as a tridimensional morphological frame, strictly limiting the height of surrounding buildings. Since there was a height control, the previous buildings tended to be low-rise and meanwhile the density would be higher to compensate the height. After the relocation of airport, the clearance requirement was also removed in this area, that is, the tridimensional morphological frame "disappear" suddenly. The new buildings in old airport could be higher than before because there's no longer strictly height control but with a lower density due to the requirement of lighting and floor ratio etc. So, the height limit could also constrain and influence the building fabrics such as the building arrangement and density.
From the satellite images, the height of buildings could be estimated by the shadows so we could depict the change of surrounding buildings by modeling. We select images from 2002 and 2015 to compare the differences in the former clearance requiring area, which is shown in figure 5-a We can find that after the airport relocation more than ten years, the surrounding buildings are still almost lowrise. In figure 5-b, there are few changes along the aircraft runway extension line. Although the strong limit to building height is removed instantly, the old buildings influenced by it would not grow higher in a short time because of a very high cost to rebuild or add storeys. On comparison, in area where the cost to break the limit is relatively lower and benefit is higher such as previous vacant lands or farmlands, new and much taller buildings would grow up fast. The new residential districts in old airport and the farmlands southeast the old airport are two examples.

The differences between tridimensional morphological frame as mentioned here and the other two kinds are clear. The tridimensional frame is not a touchable one but usually a regulation, that is, the linear and planar (ground plan) have physical impacts on later plan but tridimensional one exerts an intangible control. What's more, because the regulation property of the tridimensional frame, it is usually tied with some specific buildings or areas. Once the building or site is removed or the function is abandoned, this property would also disappear. So, after the relocation of airport, the intangible tridimensional morphological frame disappeared instantly while the physical linear and planar ones could continue existing for a relatively long time.

As to the rate of breaking through the limit
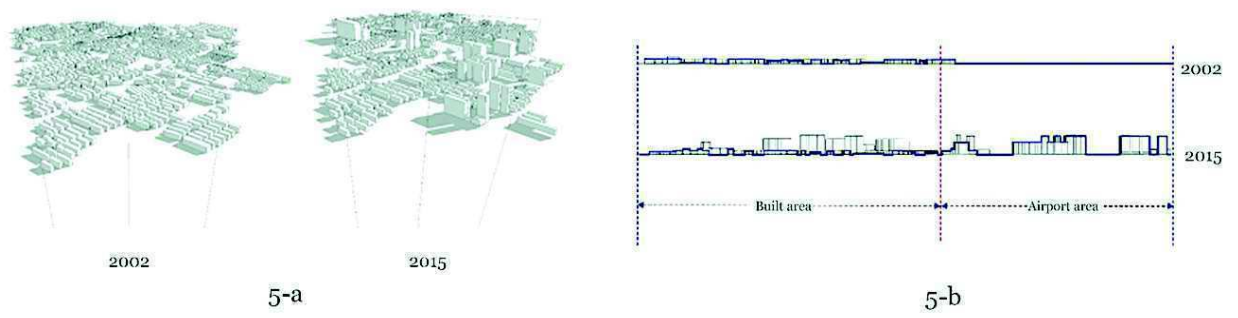

Figure 5.

Spatial model of old airport clearance area 
of former frames, there also a difference. The physical frames could be broken through easily just by demolishing and rebuilding. Although some residuals would function as morphological frames to restrict the later construction, most of physical existence would be destroyed with a relatively high speed. In comparison, although the tridimensional limit disappears thoroughly after relocation, the spatial expression of former morphological frame could be distinguished from the old buildings in a long time because the old buildings would not be pulled down and rebuilt taller soon on account of the very high cost.

Actually, these three kinds of morphological frames function together on influencing later town plan, and they also connect with each other. The linear morphological frame like street could constrain the plot division, which may later function as a planar morphological frame. The shape of plots and the tridimensional frame could impact the height and the arrangement of buildings. They function together to decide the regional urban morphology.

\section{Conclusion}

From this case, the connotation of morphological frame could be extended to tridimensional aspect, and this aspect is becoming increasingly important with the rapid development of building technology and more and more stress on spatial regulation today. There are tremendous tall buildings in modern cities which is quite different with 1960s' Alnwick whose buildings were commonly lowrise, and this means some concepts including morphological frame should be refined.

Besides the case of airport, the height control around some historical sites to protect the historical and traditional features such as the Old Summer Palace (Yuanming Yuan) is also an example of tridimensional morphological frame. Generally, the height limit regulation is compulsory as long as the building or site exist. So, from another viewpoint, the tridimensional frame can be regarded as an indigenous property connected with the function of a building or site. Once the function changes, the tridimensional morphological frame also change or disappear. In this respect, the concept morphological frame does not only express as physical existences but also spatial regulation carried by certain buildings or sites.

Under Chinese background especially the governmental background, representative as a strong government, the stability of linear and planar morphological frames i.e. the streets and ground plan is not so good as western cities such as Alnwick. Having a relatively stronger power, the government can usually make significant changes in a large area according to the city plan. And of course, the cost is also taken into consideration in this process. In Conzen's research, the cost (not only the monetary) is the main factor that decides the stability of street plans, while in this case, the different cost is also the main reason why street plan changes fast and the old buildings show a slower change. The administrative power is strongest in the construction of regional framework like main roads, but the government also takes the existed lanes into consideration in minor plan to reduce cost and unnecessary influence. So the stability of plan elements and the strength of morphological frame is closely related to the cost.

\section{References}

Conzen, M. P. (2009) 'How cities internalize their former urban fringes: a cross-cultural comparison', Urban Morphology 13(1), 29.

Conzen, M. R. G. (1969) Alnwick, Northumberland: a study in town-plan analysis (Institute of British Geographers, London), 127.

Lin, Y., De Meulder, B. and Wang, S. (2011) 'From village to metropolis: a case of morphological transformation in Guangzhou, China', Urban Morphology 15(1), 5-20.

Whitehand, J. W. R. (2001) 'British urban morphology: the Conzenion tradition', Urban Morphology 5(2), 103-109.

Whitehand, J. W. R., Conzen, M. P. and Gu, K. (2016) 'Plan analysis of historical cities: a Sino-European comparison', Urban Morphology 20(2), 139-158. 